\title{
Effect of diet on faecal and urine urobilinogen excretion and its possible relationship to the pathogenesis of peptic ulceration
}

\author{
S. L. MALHOTRA ${ }^{1}$ \\ From the Medical Department, Western Railway, Bombay, India
}

In the course of studies of certain biochemical values in two population groups, namely, the South Indians versus the North Indians, showing disparate incidence rates from ischaemic heart disease (Padmavati, 1962; Malhotra, 1967a, and b 1968 ) and peptic ulcer (Dogra, 1940; Hadley, 1959; Malhotra, 1964) there were impressive differences in their faecal urobilinogen concentration (Malhotra, 1966). The mean values for faecal urobilinogen concentration were significantly higher in the South Indian men compared with those for the North Indian men and also significantly higher in men than in women (Malhotra, $1966,1967 \mathrm{~b}$ ), and it seemed likely that the pattern of diet and eating reported elsewhere (Malhotra, 1964, 1967a, 1968) played a part.

In this paper an opportunity was taken to determine whether these differences in the faecal urobilinogen concentration between the two population groups could be reproduced in feeding experiments under controlled conditions.

\section{MATERIAL AND METHODS}

Twenty-seven convalescent patients, all men, suffering from diseases unrelated to the gastrointestinal tract, were randomly included in this investigation and for the purpose of these studies were transferred to the metabolic ward of the Jagjivan Ram Hospital of the Western Railway. They were all ambulatory. Sixteen were cases of bone injuries of the upper limbs; five of ocular injuries; three convalescent burns cases; one operated case of osteomyelitis; and the remaining two of pulmonary tuberculosis. During the investigation none of the patients received any oral or parenteral medication for his original condition.

DIETARY REGIMENS The patients were given two different diets: the North Indian style masticatory wheat diet for 15 days and the South Indian style diet comprising boiled rice and hot lentil soups for another 15 days. (For

${ }^{1}$ Present address and address for reprints: Chief Medical Officer and Head of the Medical Department, South Eastern Railway, Garden Reach, Calcutta 43, India.
TABLE I

CONSTITUENTS OF SOUTH INDIAN NON-MASTICATORY AND NORTH INDIAN MASTICATORY DIETS USED IN THE FEEDING EXPERIMENTS (G PER DAY)

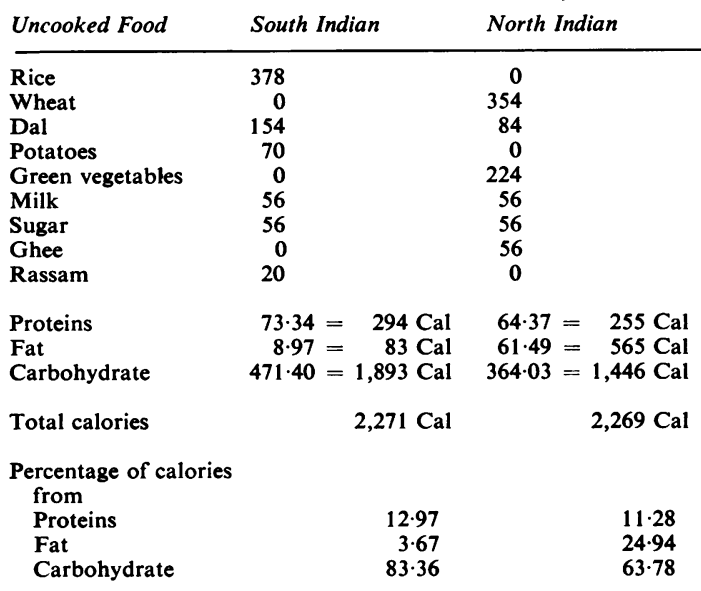

a description of the diets see Malhotra, Saigal, and Mody, 1965, and Table I.) To eliminate the effect of energy outputs, the diets were isocaloric with each other at 2,271 calories in each diet. In order to eliminate any bias due to individual differences in the diet, patients were served from a common pool of the respective diets. In the first set of experiments, which included 12 patients, the masticatory wheat diet was used for 15 days, followed by the non-masticatory rice diet; and in the remaining 15 patients, the non-masticatory rice diet preceded the masticatory wheat diet.

FAECAL AND URINE STUDIES Faeces were passed directly into marked, specially designed containers so that contamination with urine could not take place while passing stools into them. The patients were also specifically instructed to avoid any contamination of the faeces with urine.

Faecal urobilinogen concentration was estimated in duplicate by the method of Maclagan (1946) in a threeday stool collection (for the last three days on each dietary 
regimen), the results being given as milligrams of urobilinogen per $100 \mathrm{~g}$ of stool. From both the urobilinogen concentration and the bulk of the stool the daily urobilinogen excretion in milligrams per 24 hours can be calculated.

Urine urobilinogen excretion was estimated by the method of Watson (1936), in the first set of 12 patients only, and this investigation, due to certain technical difficulties, could not be done in the remaining 15 patients. The results have been expressed in milligrams per 24 hours.

\section{RESULTS}

FAECAL UROBILINOGEN CONCENTRATION These results are summarized in Tables II, III, and IV. In all the 27 patients a reduction in the faecal urobilinogen concentration occurred on the sloppy rice diet as compared with the masticatory wheat diet; the mean values fell from 71.6 to $19.8 \mathrm{mg} / 100 \mathrm{~g}$ stool. The mean weight of stool fell in 22 out of the 27 patients on the South Indian rice diet as compared with the North Indian wheat diet (Table II). The mean figures for excretion were 99.6 and $53.9 \mathrm{mg} / 24$ hours on rice versus wheat diets respectively (Table III).

URINE UROBILINOGEN EXCRETION In all the 12 patients there was a rise in the urine urobilinogen

TABLE II

MEAN FAECAL UROBILINOGEN CONCENTRATION (MG/100 G STOOL) WITH WHEAT AND RICE DIETS IN 27 ADULTS

\begin{tabular}{|c|c|c|}
\hline Subject & Wheat Diet & Rice Diet \\
\hline 1 & $44 \cdot 6$ & 117.4 \\
\hline 2 & 10.2 & 60.9 \\
\hline 3 & 26.0 & 118.4 \\
\hline 4 & $20 \cdot 2$ & 56.6 \\
\hline 5 & 8.4 & 95.8 \\
\hline 6 & $37 \cdot 1$ & 107.6 \\
\hline 7 & 16.8 & $63 \cdot 3$ \\
\hline 8 & 21.9 & $24 \cdot 4$ \\
\hline 9 & 32.8 & 115.3 \\
\hline 10 & $20 \cdot 6$ & 91.0 \\
\hline 11 & $18 \cdot 7$ & $62 \cdot 8$ \\
\hline 12 & $16 \cdot 4$ & $71 \cdot 7$ \\
\hline 13 & $51 \cdot 4$ & $78 \cdot 3$ \\
\hline 14 & $28 \cdot 1$ & 130.4 \\
\hline 15 & $28 \cdot 6$ & 69.9 \\
\hline 16 & 12.2 & 87.0 \\
\hline 17 & 26.2 & 26.7 \\
\hline 18 & $13 \cdot 1$ & 43.6 \\
\hline 19 & 16.4 & 43.6 \\
\hline 20 & $16 \cdot 4$ & 123.3 \\
\hline 21 & $11 \cdot 2$ & $25 \cdot 3$ \\
\hline 22 & 19.7 & $76 \cdot 4$ \\
\hline 23 & $7 \cdot 3$ & 32.8 \\
\hline 24 & $9 \cdot 2$ & 41.0 \\
\hline 25 & 7.0 & $45 \cdot 3$ \\
\hline 26 & $7 \cdot 3$ & $49 \cdot 2$ \\
\hline 27 & $6 \cdot 5$ & $76 \cdot 2$ \\
\hline \multirow[t]{2}{*}{$\begin{array}{l}\text { Mean } \\
\text { S.E. }\end{array}$} & $\begin{array}{c}19 \cdot 8 \\
2 \cdot 24\end{array}$ & $\begin{array}{c}71 \cdot 6 \\
6 \cdot 20\end{array}$ \\
\hline & $t=9.37$ & \\
\hline
\end{tabular}

TABLE III

MEAN WEIGHT OF FAECES EXCRETED (G/24 HOURS) WITH WHEAT AND RICE DIETS IN 27 ADULTS

Subject

Wheat Diet Rice Diet

\begin{tabular}{|c|c|c|}
\hline Subject & Wheat Diet & Rice Diet \\
\hline 1 & 253 & 144 \\
\hline 2 & 279 & 94 \\
\hline 3 & 391 & 184 \\
\hline 4 & 231 & 140 \\
\hline 5 & 188 & 88 \\
\hline 6 & 231 & 54 \\
\hline 7 & 216 & 265 \\
\hline 8 & 40 & 171 \\
\hline 9 & 241 & 64 \\
\hline 10 & 426 & 120 \\
\hline 11 & 514 & 165 \\
\hline 12 & 215 & 24 \\
\hline 13 & 254 & 64 \\
\hline 14 & 382 & 46 \\
\hline 15 & 359 & 305 \\
\hline 16 & 472 & 57 \\
\hline 17 & 199 & 532 \\
\hline 18 & 427 & 428 \\
\hline 19 & 219 & 203 \\
\hline 20 & 42 & 35 \\
\hline 21 & 145 & 347 \\
\hline 22 & 41 & 91 \\
\hline 23 & 381 & 365 \\
\hline 24 & 478 & 415 \\
\hline 25 & 321 & 92 \\
\hline 26 & 489 & 163 \\
\hline 27 & 278 & 144 \\
\hline \multirow[t]{2}{*}{$\begin{array}{l}\text { Mean } \\
\text { S.E. }\end{array}$} & $\begin{array}{l}285 \\
26 \cdot 19\end{array}$ & $\begin{array}{l}178 \\
26 \cdot 34\end{array}$ \\
\hline & $\begin{array}{l}t=3.22 \\
P<0.01\end{array}$ & \\
\hline
\end{tabular}

TABLE IV

MEAN FAECAL UROBILINOGEN EXCRETION (MG/24 HOURS) WITH WHEAT AND RICE DIETS IN 27 ADULTS

\begin{tabular}{|c|c|c|}
\hline Subject & Wheat Diet & Rice Diet \\
\hline 1 & 112.84 & 169.08 \\
\hline 2 & $28 \cdot 40$ & $57 \cdot 24$ \\
\hline 3 & 101.66 & 217.85 \\
\hline 4 & 46.66 & 79.24 \\
\hline 5 & 15.79 & 84.30 \\
\hline 6 & $85 \cdot 70$ & $58 \cdot 10$ \\
\hline 7 & $36 \cdot 28$ & $167 \cdot 74$ \\
\hline 8 & 8.76 & $41 \cdot 72$ \\
\hline 9 & 79.04 & 73.79 \\
\hline 10 & $87 \cdot 75$ & $109 \cdot 2$ \\
\hline 11 & $96 \cdot 12$ & 103.60 \\
\hline 12 & $35 \cdot 26$ & $17 \cdot 20$ \\
\hline 13 & 130.55 & $50 \cdot 10$ \\
\hline 14 & $107 \cdot 34$ & 59.98 \\
\hline 15 & 102.67 & $213 \cdot 10$ \\
\hline 16 & $57 \cdot 58$ & 49.60 \\
\hline 17 & $52 \cdot 14$ & 142.07 \\
\hline 18 & 55.93 & 186.60 \\
\hline 19 & 35.98 & 88.50 \\
\hline 20 & 7.05 & $43 \cdot 15$ \\
\hline 21 & $16 \cdot 24$ & 87.91 \\
\hline 22 & 8.07 & $69 \cdot 52$ \\
\hline 23 & 27.81 & 119.72 \\
\hline 24 & 43.97 & $170 \cdot 15$ \\
\hline 25 & $22 \cdot 47$ & 41.67 \\
\hline 26 & 35.69 & $80 \cdot 19$ \\
\hline 27 & 18.07 & $109 \cdot 72$ \\
\hline \multirow[t]{2}{*}{$\begin{array}{l}\text { Mean } \\
\text { S.E. }\end{array}$} & $\begin{array}{c}53.9 \\
7.08\end{array}$ & $\begin{array}{l}99.6 \\
10.52\end{array}$ \\
\hline & $\begin{array}{l}t=4.10 \\
P<0.001\end{array}$ & \\
\hline
\end{tabular}


TABLE V

MEAN URINE UROBILINOGEN EXCRETION (MG/24 HOURS) ON WHEAT AND RICE DIETS IN 12 ADULTS

\begin{tabular}{ccc} 
Subject & Wheat Diet & Rice Diet \\
\hline 1 & 0.0386 & 1.4000 \\
2 & 0.0534 & 1.1327 \\
3 & 0.5830 & 0.8262 \\
4 & 0.0653 & 2.4725 \\
5 & 0.1600 & 2.6724 \\
6 & 0.0760 & 0.3223 \\
7 & 0.0620 & 0.9160 \\
8 & 0.3610 & 1.3479 \\
9 & 0.8300 & 3.7024 \\
10 & 0.0960 & 0.3668 \\
11 & 0.1220 & 0.0817 \\
12 & 0.2390 & 0.1312 \\
Mean & 0.2238 & 1.2810 \\
S.E. \pm & 0.072 & 0.393 \\
& $\mathrm{t}=3.50$ & \\
& $\mathrm{P}<0.01$ &
\end{tabular}

excretion when the North Indian wheat regime was changed to the South Indian rice regime, the mean values being $0.22 \mathrm{mg}$ and $1.28 \mathrm{mg} / 24$ hours on wheat versus the rice diets. These values are summarized in Table V.

\section{INTERPRETATION AND VALIDITY OF THE RESULTS}

Even though the mean stool weight rose on the wheat diet as compared with the rice diet $(P<0.01)$ the fall in the urobilinogen concentration $(\mathrm{mg} / 100 \mathrm{~g}$ of stool) on wheat diet is not due to dilution because the excretion of faecal urobilinogen ( $\mathrm{mg} / 24$ hours) also fell significantly $(P<0.001)$. The mean stool weight $(\mathrm{g} / 24$ hours) is significantly higher on wheat diet as compared with the rice diet, probably because the North Indian style diet is rich in cellulose and vegetable fibre, whereas the South Indian style diet is poor in these. Our studies of the microscopic examination of stools for vegetable fibres in North Indians versus the South Indians showed that whilst the stools in the former had an abundance of cellulose and vegetable fibres, these were hardly present in the stools of the South Indians (Malhotra, 1967a, b).

Urobilinogen is a term used to include a class of compounds all derived by bacterial breakdown of bilirubin (Watson, 1936). Bilirubin is excreted by the liver via the common bile duct into the intestine both in the free form as well as in the form of bilirubinmonoglucuronide and bilirubin-diglucuronide. Only a small portion of bilirubin is reabsorbed from the intestine. Most of it passes down the colon, where it comes in contact with the reducing enzymes of anaerobic bacteria and is reduced into three colourless compounds of very similar composition, namely, D-urobilinogen, mesobilirubinogen, and stercobilinogen. These are collectively called urobilinogen. Up to $50 \%$ of the urobilinogen of the colon is re- absorbed into the portal circulation and returned to the liver to be re-excreted as bile. The remaining $50 \%$ or more of the intestinal urobilinogen is excreted into the stool (Hoffman, 1964). Thus, under normal circumstances, the amount of urobilinogen excreted in the faeces depends primarily on the amount of bilirubin entering the intestine (Varley, 1962), and this can thus provide an indirect index of the amount of bile entering the intestinal lumen.

One inference of our results, therefore, is that significantly larger amounts of bilirubin enter the intestinal lumen when the diet is the non-masticatory, South Indian style boiled rice and hot lentil soups as compared with the masticatory, North Indian style wheat chappattis and dals. The validity of this observation has been tested by comparing the urine urobilinogen excretion on these two different dietary regimens. Traces of urobilinogen up to $4 \mathrm{mg}$ per day escape removal from the blood by the liver and are carried to the kidneys to be excreted in the urine as urine urobilinogen (Hoffman, 1964). Since urine urobilinogen is derived from that part of the urobilinogen absorbed in the intestine which is not excreted by the liver, the amount present in the urine depends upon the amount of bilirubin entering the intestine (Varley, 1962); the significantly higher urine urobilinogen excretion on the South Indian style rice diet as compared with the North Indian wheat diet in all the 12 patients in whom this investigation was done confirms the inference that higher amounts of bile enter the intestinal lumen on the South Indian diet as compared with the North Indian diets.

As a second test of these differences the faecal urobilinogen concentration $(\mathrm{mg} / 100 \mathrm{~g}$ stool) and urine urobilinogen excretion $(\mathrm{mg} / 24$ hours) was compared in a survey of railroad employees on their habitual diets from South India as compared with North India. These results, which have been reported elsewhere (Malhotra, 1966, 1967b), showed significantly larger concentrations of faecal urobilinogen among the South Indians as compared with the North Indians $(\mathrm{P}<0.001, \mathrm{n}=55)$, the respective mean values being $64.4 \mathrm{mg}$ and $19.8 \mathrm{mg} / 100 \mathrm{~g}$ stool. Similarly, the figures for urine urobilinogen excretion in this survey were $1.39 \mathrm{mg}$ and $0.18 \mathrm{mg} / 24$ hours $(\mathrm{P}<0.01, \mathrm{n}=23)$.

Why the values were lower in women than in men, even though their diets were identical with men, is less clear but may be explained by the fact that women habitually masticate their food better and take a longer chewing time for their meals (Malhotra, 1967c).

\section{DISCUSSION}

Evidence is presented elsewhere (Malhotra, 1968) that the rise in the faecal urobilinogen excretion on 
the South Indian style non-masticatory diet as compared with the North Indian style masticatory diet is not entirely due to the differences in the pattern of diet but chiefly due to the differences in the pattern of eating. These significant differences, which are an indirect measure of the amounts of bile entering the intestinal lumen, have practical implications. Peptic ulcer is notably more common in South Indians whose habitual diets are non-masticatory as compared with North Indians whose habitual diets are masticatory in nature. Lawson (1964) has presented unequivocal experimental evidence that shows that when the highly alkaline bile is led into the stomach it leads to a more than 40 -fold increase in mitotic activity, producing changes of chronic gastritis. Marks and Shay (1959), du Plessis (1965), and Spira $(1956,1965)$ have shown that this chronic gastritis predisposes to chronic gastric ulcer. The relation of chronic gastritis to gastric ulcer parallels that of chronic duodenitis to chronic duodenal ulcer (for references, such as Rivers, Taylor, and Templeton, see Spira, 1956). In an alkaline milieu the intracellular mucus of the gastroduodenal mucosa is rendered fluid and is removed from the cell (Ball and James, 1961) and this might explain why an excess of highly alkaline bile when led into the stomach gives rise to chronic gastritis, predisposing to ulceration (Lawson, 1964; du Plessis, 1965; Malhotra, 1966). Since the reaction of the bile depends upon its flow rate, because with an increase in the flow rate of bile its $\mathrm{HCO}_{3}$ content increases, while bile which has been stored in the gallbladder loses water as well as bicarbonate, with the result that in the highly concentrated gallbladder bile, the concentration of bicarbonate is very low, being about $5 \mathrm{mEq} / 1$ in hepatic bile flowing at the rate of $0.1 \mathrm{ml} / \mathrm{min}$ the corresponding figure is $10 \mathrm{mEq} / \mathrm{l}$ (Magee, 1962), we suppose that the bile entering the duodenal lumen in patients on non-masticatory regimes will be more alkaline than in those on masticatory diets. This may explain the greater frequency of peptic ulcer among South Indians eating sloppy diets as compared with the North Indians habituated to masticatory foods (Malhotra, 1964, 1965; Malhotra et al., 1965; Malhotra, 1966).

\section{SUMMARY}

Faecal and urine urobilinogen rise in nearly all patients when their diets are changed from the masticatory, North Indian style, wheat chappattis and dal, to the non-masticatory, South Indian style, boiled rice and lentil soups. A similar trend is noted in a population survey of North Indians versus South Indians consuming their habitual diets. These values provide an indirect measure of the amount of bile entering the duodenal lumen in these two disparate population groups consuming different diets, and habituated to disparate patterns of eating. Since an excess of bile, due to its highly alkaline reaction, will dissolve the intracellular mucus of the gastroduodenal mucosa and thus produce chronic gastritis or chronic duodenitis predisposing to ulceration, it is interesting to speculate if the explanation of the rarity of ulcer disease among North Indians as compared with the South Indians may lie in their significantly lower values of the amounts of bile entering their duodenal lumen.

I am grateful to Mr. H. J. Acharya, M.Sc., chief technician at the laboratory at the Jagjivan Ram Hospital, for his help in the biochemical studies; to Dr. (Mrs.) C. D. Punwani who supervised the diets; and to the many patients included in these experiments without whose willing cooperation this study could not have been possible.

\section{REFERENCES}

Ball, P. A. J., and James, A. H. (1961). The histological background to gastric ulcer. Lancet, 1, 1365-1367.

Dogra, J. R. (1940). Studies on peptic ulcer in South India. I. Introduction and clinical study of 258 cases. Indian J. med. Res. 28, 145-161.

du Plessis, D. J. (1965). Pathogenesis of gastric ulceration. Lancet, 1, 974-978.

Hadley, G. C. (1959). Studies of peptic ulcer as found in South India. Indian Coun. med. Res. Rep. No. 39, 31-33.

Hoffman, W. S. (1964). The Biochemistry of Clinical Medicine, 3rd ed., pp. 375-378. Year Book Medical Publishers, Chicago.

James, A. H. (1957). The Physiology of Gastric Digestion. Arnold, London.

Lawson, H. H. (1964). Effect of duodenal contents on the gastric mucosa under experimental conditions. Lancet, 1, 469-472.

Maclagan, N. F. (1946). Faecal urobilinogen: clinical evaluation of a simplified method of estimation. Brit. J. exp. Path., 27, 190-200.

Magee, D. F. (1962). Gastro-intestinal Physiology, p. 68. Thomas, Springfield, Illinois.

Malhotra, S. L. (1964). Peptic ulcer in India and its aetiology. Gut, 5, $412-416$.

(1965). Peptic ulcer: role of saliva in its aetiology. J. Ass. Phycns India, 13, 907-914.

- (1966). Pathogenesis of peptic ulcer. Abstr. 3rd Wld Congr. Gastroenterology, Tokyo, Japan, pp. 69-70.

- (1967a). Geographical aspects of acute myocardial infarction in India with special reference to patterns of diet and eating. Brit. Heart J., 29, 33-34.

(1967b). Serum lipids, ischaemic heart disease and dietary factors. Amer. J. clin. Nutr. 20, 462-474.

- (1968d). Effect of pattern of eating and antacids on faecal urobilinogen excretion. Gut, 9

- (1967c). An epidemiological study of peptic ulcer in South of India and the ulcer change. Gut, 8, 180-188.

_- Saigal, O. N., and Mody, G. D. (1965). Role of saliva in the aetiology of peptic ulcer. Brit. med.J., 1, 1220-1222.

Marks, I. N., and Shay, H. (1959). Observations on the pathogenesis of gastric ulcer. Lancet, 1, 1107-1111.

Padmavati, S. (1962). Epidemiology of cardiovascular disease in India. Ischemic heart disease. Circulation, 25, 711-717.

Spira, J. J. (1956). Gastro-duodenal Ulcer, p. 186. Butterworth, London. (1965). Pathogenesis of gastric ulceration. Lancet, 2, 182-183.

Varley, H. (1962). Practical Clinical Biochemistry, 3rd ed., p. 296 Heinemann, London.

Watson, C. J. (1936). Studies in urobilincgen. I. An improved method for the quantitative estimation of urobilinogen in urine and feces, pp. 294-295. Cited by Varley. Amer. J clin. Path., 6 $458-475$ (1962). 